\title{
CHINESE COMPARISONS AND QUESTIONABLE ACTS
}

\author{
Barbara Herrnstein Smith
}

Andreas Roepstorff's description of cultural neuroscience, taken together with Geoffrey Lloyd's coincidentally related comment here, reminded me of a visit I made to China in 1983 with a group of American scholars of comparative literature. Since the discipline of comparative literature as such did not exist at the time in Chinese universities, I was repeatedly asked by the Chinese scholars we met to explain the sort of research we did. I usually began by saying something like, "Well, someone who specializes in English and Chinese literature might compare the themes or plots of Elizabethan drama and Peking opera." The response I almost invariably received was, "And which is better?" I was, of course, amused but also puzzled by this. Were these scholars, I wondered, attempting — teasingly or otherwise - to elicit a betrayal of my presumed Western snobbery? Or did their experience of the recently ended Cultural Revolution make them sensitive about the status of traditional Chinese culture? Or perhaps the only Chinese term available to translate comparative involved ideas of ranking or preference, so that, for my interlocutors, comparing things just meant seeing or saying which was better.

I never arrived at a satisfactory resolution to my puzzlement, either from my respectfully posed but language- and custom-tangled questions at the time or from subsequent conversations, some of them rather awkward, with the

Common Knowledge 17:1

DOI 10.1215/0961754X-2010-034

๑ 2011 by Duke University Press 
Chinese-American scholars in our group. In their very inevitability, however, these old perplexities are relevant here. For they illustrate vividly the conceptual and methodological — and, I would add, sometimes ethical — hazards of intercultural comparison to which Lloyd alerts us; and, accordingly, they suggest why the technologically and otherwise inventive studies described by Roepstorff must be approached with some wariness.

Here as elsewhere in his work, Lloyd is especially attentive to the complex play of difference and sameness in cultures and cognition. Indeed, complexityas distinct from simple contrast or binarism of any kind - is his signature theme as a classicist and comparatist. ${ }^{1}$ Thus he notes similarities as well as differences in ancient Chinese and ancient Greek responses to cultural difference and also the significantly different views of these matters among the Greek philosophers themselves. In the same vein, discussing studies of cultural/linguistic variability or counterclaimed universality among humans in color perception, he stresses the complexity of such cognitive activities, including the ongoing interactions among the multiple variables presumably involved. Noting the challenge that such intrinsic complexity and inevitable interactivity present to standard dichotomies of universality and cultural relativity, Lloyd observes that these and other familiar dualisms have been made obsolete by a century of research in genetics, ethnography, psychology, and related empirical disciplines.

Traditional dichotomies and related dualisms can, however, be extremely resilient, even among practitioners of the empirical disciplines themselves. Thus Lloyd's cautions appear especially apt with regard to the contrasts drawn or assumed in some of the studies described by Roepstorff. Among other troubling features of those studies is the casually shifting nomenclature used by researchers to frame questions and conclusions. Can it be proper, one wonders, to move without comment from "Chinese" to "Asians" and from "White [sic] American students" to "Westerners"? And, if the rather obviously different cultures of, say, Norwegian fishermen, Spanish flamenco dancers, and the college-age children of middle-class Americans are judged insignificant in regard to the cognitive traits at issue, then one must wonder what explains the exclusion, as it appears, of black Americans from the pool of experimental subjects. Conflations and exclusions of these kinds lead one to suspect that the terms "Asian/s" and "Western/ers" are operating in these studies not (or not only) to describe persons distinguished by the particular cultures they inhabit but (or to some extent also) as biological-racial

I. See, e.g., G. E. R. Lloyd, Demystifying Mentalities (New York: Cambridge University Press, I990); Ancient Worlds, Modern Reflections: Philosophical Perspectives on Greek and Chinese Science and Culture (New York: Oxford University Press, 2004); Cognitive Variations: Reflections on the Unity and Diversity of the Human Mind (New York: Oxford University Press, 2007). 
categories. To the extent such suspicions are warranted, claims made by cultural psychologists regarding the putatively contrasting cognitive traits of "Asians" and "Westerners" (as, for example, having "interdependent" versus "independent" views of the self or being "collectivist" versus "individualistic" in regard to other people) appear problematic, both conceptually and methodologically dubious and, in some contexts, at least potentially invidious ("And which is better?"). ${ }^{2}$

A number of the problems noted here are evident in a foundational crosscultural study that Roepstorff cites, "Culture and the Self," by psychologists Hazel Markus and Shinobu Kitayama. ${ }^{3}$ Its authors' stated objectives suggest a corrective intention directed at the provincialism of much psychological research, similar to the disciplinary self-disciplining efforts of the historians and anthropologists that I describe in "The Chimera of Relativism." Thus, commenting on psychologists' tendency to overgeneralize from findings on particular local populations, Markus and Kitayama write:

$[M]$ ost of what psychologists currently know about human nature is based on one particular view - the so-called Western view of the individual as an independent, self-contained, autonomous entity. ... As a result of this monocultural approach to the self[,] ... psychologists' understanding of those phenomena that are linked in one way or another to the self may be unnecessarily restricted. ${ }^{4}$

Their central aim, however, is to establish the psychological significance of what they assume from the beginning are two specific, sharply contrasted ways in which people "view the self." 5

Some basic difficulties of conceptualization in the article - and, thereby, in the tradition of cross-cultural research that it continues to generate, including recent neuroscience studies cited by Roepstorff_ can be seen in the authors' introductory statement:

In this article, we suggest that construals of the self, of others, and of the relationship between the self and others may be even more powerful than previously suggested and that their influence is clearly reflected in differences among cultures. ${ }^{6}$ In particular, we compare an independent

2. See Richard E. Nisbett, The Geography of Thought: How Asians and Westerners Think Differently . . and Why (New York: Free Press, 2003), for extended contrasts of these kinds based on such studies.

3. Hazel Markus and Shinobu Kitayama, "Culture and the Self: Implications for Cognition, Emotion, and Motivation," Psychological Review 98.2 (I99I): 224-53

4. Markus and Kitayama, "Culture and the Self," 224.

5. The assumption is based largely on earlier studies by H. C. Triandis and others that are comparably problema- tic. For discussion of the lineage and some of the problems, see Douglas L. Medin, Sara J. Unsworth, and Lawrence Hirschfeld, "Culture, Categorization, and Reasoning," in Shinobu Kitayama and Dov Cohen, Handbook of Cultural Psychology (New York: Guilford, 2007), 615-44.

6. The direction of the causality or influence claimed by cultural psychologists - whether from culture to cognition or vice versa - varies from one study to another or is essentially ambiguous. In this passage, a cognitive trait ("construals of the self") is said to be "reflected in" cultural differences. But that is the reverse of the claim made in 
view of the self with one other, very different view, an interdependent

As the latter part of this statement makes clear, Markus and Kitayama seek to be scrupulous in indicating the specificity of the groups whose presumptively sharply different "views of the self" concern them. Indeed, additional caveats and further qualifications are added immediately and pile up over the course of the lengthy article: "The distinctions that we make ... must be regarded [only] as general tendencies ... The prototypical American view of the self ... may prove to be most characteristic of White, middle-class men with a Western European ethnic background." ${ }^{\circ}$ A footnote here adds: "The prototypical American view may also be further restricted to a particular point in history. It may be primarily a product of late, industrial capitalism." Indeed it may be, but the authors do not consider the sizeable implications of that possibility for their research. A cascade of further qualifications appears at the conclusion of the article:

[T] here may well be important distinctions among those views [of the self] we discuss as similar and . . . there may be views of the self and others that cannot easily be classified as either independent or interdependent. Another thorny issue centers on the assessment of cultural differences. ... Another persistent issue is that of translation and equating stimuli and questionnaires. ${ }^{9}$

And so forth: the final paragraph continues in this way for several more sentences. The acknowledgment of such problems is, of course, admirable as such. But, as the authors' caveats cut more deeply into their claims and as the issues they identify become thornier and more fundamental, it becomes increasingly difficult to say exactly what their studies reveal about "Asian" versus "Western" "views of the self" and what, if anything, they demonstrate about the influence of culture on cognition (or vice versa).

other studies cited by Roepstorff that cognitive traits (and correlated brain activities) differ as influenced by - or as a reflection of-cultural difference (see, e.g., J. Y. Chiao, ed., Cultural Neuroscience: Cultural Influence on Brain Function [Amsterdam: Elsevier, 2009]). Only claims of the latter kind, of course, would make the new field of cultural neuroscience a site of "cultural relativism" as the term is commonly understood.
7. Markus and Kitayama, "Culture and the Self," 224.

8. Markus and Kitayama, "Culture and the Self," 225. 9. Markus and Kitayama, "Culture and the Self," 247. 
Evidently recognizing the possibility of such a skeptical reaction, Markus and Kitayama make a final point of interest here. "A failure to replicate certain findings in different cultural contexts," they write, "should not lead to immediate despair over the lack of generality of various psychological principles or to the conclusion of some anthropologists that culturally divergent individuals inbabit incomparably different worlds." 10 The otherwise gratuitous-seeming disavowal of this latter rather extravagant idea, a disavowal repeated, as Roepstorff notes, in other studies he cites, appears to have become something of a ritual in cross-cultural research. Allusion to and rejection of just that idea also appears, we recall, in a passage I discuss by Scott Atran, who explicitly identifies the rejected idea with "cultural relativism." In each case, rejection of the vaguely attributed idea that culturally divergent humans "inhabit incomparably different worlds" is attached to a strong affirmation of the existence of general psychological principles and/or universals of human nature. And, in each case, that affirmation is offered in the face of, and in order to discount, evidence of significant cultural variability in a cognitive trait said to be crucial in human behavior.

Roepstorff is eager to represent cultural cognitive neuroscience as a site of contemporary cultural relativist energy. Perhaps it will, in time, become such. At the moment, however, a good bit of research in the field seems to be otherwise motivated and directed.

After a professional lifetime of being hooted for "extreme," "radical," "all-theway-down" relativism, it is bracing to be charged with not being relativistic enough, especially by so artful a challenger as Martin Holbraad. But the hooters had it right all along, at least under definitions of relativism that I have taken care to spell out. Most of the supposedly radicalizing moves that Holbraad urges have been evident in my work from the beginning, ${ }^{11}$ and the other moves he urges either are not especially radical from my perspective or would be at odds otherwise with my tastes or purposes. No one engaged by literary and linguistic theory over the past half century needs to be told that the meaning of the term relative is itself relative or that the scope of an assertion of relativity can include itself. And, while reveling in semantic and conceptual proliferation is certainly an available activity, I would not myself forego other intellectual pursuits to indulge in it overmuch. Similarly, while I would, like Holbraad, stress the intellectual productivity of intellectual controversy (the point is central to Belief and Resistance), I have been no less interested in exploring the rhetorical, psychological, and social-

Io. Markus and Kitayama, "Culture and the Self," 247, emphasis added.
I I. See, e.g., Barbara Herrnstein Smith, "Contingencies of Value," Critical Inquiry Iо.I (1983): I-35: "All value is radically contingent." 
institutional operations and effects of such controversies. ${ }^{12}$ Moreover, while I have certainly partaken of what he celebrates as the pleasures of "oppositional differentiation" (though he interprets it, in my case, as "macho" combativeness), I have also pursued, and found happiness in, more irenic ventures.

Holbraad is not obliged to be familiar with the complete works of B. H. Smith, but, had he looked more carefully at the texts he did consult, he would not have needed to guess at so many of my presumptive "positions" and "arguments." As it is, his guesses are generally quite wide of the mark. For example, I do not claim, as he supposes, "that appeals to relativity are founded on good and solidly empirical grounds." I do observe that the relativistic views of anthropologists and historians commonly arise from their experiences in the field or in the archives. But to remark a likely source is not to claim an ultimate grounding, and it takes quite a bit of inventive glossing to extract a beefy empiricist foundationalism of that kind from my stated views.

In the passage from Negotiations that Holbraad evokes at the end of his comment, Gilles Deleuze writes of his youthful impatience with the history of philosophy (he mentions Kant and Hegel) and of seeing his own early philosophical efforts as "taking an author" rudely (to use Holbraad's term) "and giving him a child that would be his own offspring, yet monstrous." "It was really important," Deleuze adds, "for it to be his own child, because the author had to actually say all I had been saying." Holbraad, evidently modeling his efforts here on Deleuze's creative overcoming of venerable philosophers, seeks accordingly to give my arguments a more fruitful turn. The attempt picks up steam with his apparent demonstration of my alleged mirror duplication of the form of the familiar charge of self-refutation ("When Smith asserts that the truth of the claim that all truth claims are relative is itself relative ...," and so forth) and moves from there to his would-be überrelativist endgame. Less diligent than Deleuze, however, in ascertaining that the authors thus "taken" had "actually sa[id]" what was attributed them, Holbraad generates this assertion by Smith out of a crucially improper paraphrase of the text he cites plus a good bit of thin air. Thus himself duplicating the definitive ploy of the antirelativists of yore, Holbraad delivers here a litter of baby chimeras.

I2. See, e.g., Smith, Belief and Resistance: Dynamics of Intellectual Controversy (Cambridge, MA: Harvard University Press, I997), I22-23: "It is out of the endless dance and clash of skepticism and belief that all knowledge emerges." 